\title{
8 Transculturally Speaking: Linguistic Diversity, Otherness and the Transformation of Public Spheres
}

The experience of linguistic difference is among the most common in human life. Every one of us from early childhood throughout all stages of life is confronted with ways of speaking (variously addressed as languages, dialects, jargon, etc.) which sound "different" to a greater or lesser extent. In the course of life, the way in which we speak changes: A word, an accent, a language, which was perceived before as strange, may become more familiar or even well-known to us. On the other hand, we may lose familiarity with languages, just as people lose familiarity with technical or sporting skills which they do not practice regularly. This may sound all very obvious. However, a series of circumstances contribute to a reduced awareness by speakers about the hybridity of both one's own and others' "languages", as well as about the ubiquity of linguistic diversity in everyday life. As a matter of fact, languages are quite commonly considered as monolithic communicative systems which are either completely acquired or not.

Sociolinguistic research on linguistic diversity has demonstrated how widespread ideas about languages and multilingualism, such as the mythologization of an idealized "mother tongue" once and forever acquired, or the perception of monolingualism as normal and multilingualism as exceptional, can differ from actual linguistic usage. In a work provocatively entitled "Nobody is monolingual", the sociolinguist Brigitta Busch (2012) has emphasized this gap and focused on the power of language and language-difference in constructing belongings as well as boundaries:

Mit dem Satz „Niemand ist einsprachig“ meine ich genau das: eine Erfahrung, die jede_r kennt, jene des Dazu-Gehörens oder eben nicht Dazu-Gehörens aufgrund unterschiedlicher Arten des Sprechens. Einsprachig wäre demnach nur, wer diese Erfahrung nie gemacht hat, wer sich im Sprechen nie als „anders“ erlebt hat. (Busch, 2012, p. 7) ${ }^{140}$

By quoting Jacques Derrida's statement “Je n'ai qu'une langue, ce n'est pas la mienne"141 (Derrida, 1996, p.13), which only appears to contradict her assertion about monolingualism, Busch stresses the power of “the other" in influencing speakers' perceptions of their own linguistic repertoires and performances. Speakers learn, for example, from the social context in which they live, to call specific linguistic varieties

140 This and the following translations are mine: "By stating 'Nobody is monolingual' I mean exactly this: the experience, which everyone is aware of, of belonging or not-belonging because of differences in one's different ways of speaking. From this perspective, the 'monolingual' would only refer to someone who has never experienced this, who has never felt as 'Other' by speaking” (Busch, 2012, p. 7). 141 "I have but one language - yet that language is not mine” (Derrida, 1996, p. 13). 
languages or dialects, and to value them according to different social conventions and political frameworks.

In a similar vein, Judith Butler (2006) refers to the subject as being constituted by the discursive power of language, that is, by the socio-cultural norms which establish what can be said or what not. Busch extends Butler's consideration by emphasizing how linguistic norms, beyond determining what can be said, also regulate how it should be said, thus influencing speakers' perceptions of the (in)adequateness of their own manner of speech (Busch, 2012, p. 36). This is particularly true when speakers, in contexts of linguistic diversity, experience a feeling of adopting a "wrong" accent, or of lacking the "right" words. In such cases, the term "linguistic inequality" expresses the heart of what is at stake. As pointed out by Jan Blommaert (2010), linguistic inequality concerns differences which become relevant in specific contexts and which are linked to the status and the power of speakers and speech communities. As a matter of fact, speakers only recognize, in their own and others' talk, those differences which they have learned to identify and to consider meaningful in specific contexts.

This chapter looks at mediatized public spheres as spaces in which, on the one hand, powerful players-featuring not only, for example, institutional and economic agencies, but also “authoritative discourses" (Foucault, 1972)-establish, strengthen and spread normative attitudes towards languages and speech communities. On the other hand, as spaces of negotiation in which alternative voices and minority groups develop ways of contesting hegemonic ideologies and practices. In light of transformations which affect what has been long addressed as "the media" and "the language(s)", this chapter deconstructs static assumptions concerning both concepts by emphasizing, on the one hand, the diversification of the media and language(s) in the context of political, technological and socio-cultural changes, on the other, the various practices which perpetuate monocultural ideologies and hierarchizations of speakers and linguistic resources.

With respect to the diversification of media, I refer to the theoretical framework of recent advances in media studies which highlight that media are not autonomous agents but are rather completely integrated in cultural and political practices. Therefore, it makes no sense to think about "media and culture", "media and language", "media and politics", etc., since these are neither separate nor separable entities. By speaking instead of mediatized cultures, languages, politics, etc., one acknowledges that both constituents of the pair are inseparably intertwined. It is the whole human experience at its various levels of action which is mediatized (Hepp, 2014; Lundby, 2009; Krotz, 2009). Similarly, it no longer appears valid to speak of a clear distinction between mass and interpersonal communication, or between private and public communication (Androutsopoulos, 2014; Livingstone, 2009). Concerning the diversification of languages and speech communities, I refer to Vertovec's term of "superdiversity" (Vertovec, 2007; Vertovec, 2010), which is also adopted in sociolinguistic research to describe the diversification of linguistic landscapes and of speakers' 
linguistic repertoires (Blommaert et al., 2009; Blommaert et al., 2011; Blommaert, 2013). In this context, a need for a change of paradigm has been expressed, which overcomes structuralist conceptualizations of language (e.g. English, Hindi, French, etc.), and conceives language rather as a "mobile complex of concrete resources" (Blommaert, 2010, p. 47) such as specific varieties, genres, registers (Blommaert, 2010; Blommaert, 2013). According to this paradigm, multilingualism is not what people have or do not have, but what the environment enables and disables (Blommaert et al., 2005). Moreover, fundamental political and social changes, such as the end of the Cold War-which transformed the dynamics of migration-or the development of the Internet-which has dramatically extended the possibilities of circulating information, of constructing virtual networks, and of participating in social interaction-have produced highly complex patterns of mobility with respect to people, communication, money, and resources in general (Blommaert, 2013; Vertovec, 2007; Vertovec, 2010). In this regard, Blommaert (2013, p. 5) points out:

The interaction of these two forces - new and more complex forms of migration, and new and more complex forms of communication and knowledge circulation - has generated a situation in which two questions have become hard to answer: who is the Other? And who are We? The Other is now a category in constant flux, a moving target about whom very little can be presupposed; and as for the We, ourselves, our own lives have become vastly more complex and are now very differently organized, distributed over online as well as offline sites and involving worlds of knowledge, information and communication that were simply unthinkable two decades ago.

In the following discussion, I will adopt this perspective and, rather than considering media and language as two different categories, for example by questioning how "the media" handle the phenomenon of multilingualism, I will highlight how various mediatized language and discourse practices do diversity vs. how they do otherness in various contexts. Instead of suggesting a "one-size-fits-all” solution for enhancing diversity in public spheres, my discussion primarily aims at showing the variety and complexity of identity affiliations, feelings, interests and ideologies at work when speakers and speech communities do publics by mediating their linguistic usage. In this context, different ways of enabling vs. disabling diversity will be compared and discussed. This will also take into consideration not only language and discourse practices, but also institutional and economic frameworks which tend to "normalize" and "standardize" both monolingualism and specific forms of linguistic hybridity which have spread in the context of the globalization of the media industry. In contrast to these practices, more recent efforts to overcoming static and monocultural attitudes to language, identity and culture will be considered in both the academic and media fields. My transcultural approach, in this context, consists in exploring the contextuality of doing diversity vs. doing otherness, and in pinpointing the gap between "lived" superdiversity and globally circulating attitudes of "normalizing", levelling and standardizing it. Against this background, processes of in- and exclusion, of enhancing vs. hindering participation, and of acknowledging vs. idealizing 
diversity will be compared by contextualizing them within the general framework of the transformation of public spheres and the globalization of media industries. Transculturality is hence considered here as anything but a cosmopolitan utopia, and indeed as a field of conflict and negotiation.

\subsection{Whose English? Transcultural Negotiations of a Global Language}

Discussions of English as "the" global language are characterized by the contrast between two opposing motives: On the one hand, the need to communicate with speakers of "other" languages, and on the other hand, speakers' concern about the risk of levelling linguistic, and consequently cultural, diversity. In these discussions, English is usually regarded as a single "whole" language of power which is spreading at the expense of "other" languages. English native speakers are regarded in this context as privileged. This is certainly not completely false. However, a (trans)cultural look at the multiple negotiations surrounding the spread of global English helps us to understand how reductive this matter appears if put in such simplistic terms.

Raymond Williams (1961/2011, pp. 251-268) stressed this fact already in 1961, when he commented on the overall spread of American English in the United Kingdom and the subsequent resistance to the "Americanization" of the so-called "Received Standard” by British speakers:

\footnotetext{
Not only have hundreds of American words, speech forms and pronunciations been taken, often unnoticed, into English, but American speech has had an influence on almost all kinds of traditional English speaking, and it is worth noticing that it works against every single sound that was identified as peculiarly "Received Standard". Moreover, by giving other accents to power and material success, it has deprived Public School English of its former monopoly in this respect. The process is still going on, but it is not simply the Americanisation of English; it is, rather, the addition of another factor to the long and complicated history of spoken English. (Williams, 1961/2011, p. 267)
}

Behind the competition between American English and British English, he noticed the emergence of a new player in the definition of the prestige of languages: the media industry. Accordingly, the media has to be taken into account by looking at the relationships between language and power.

Concerning the formation and propagation of the notion of "standard" itself, Williams dated it back to the British English of the eighteenth and nineteenth centuries. In this period, the varied speech which had characterized the spoken language in earlier times, and which had also progressively enriched the written language, as documented by the Elizabethan dramatists, became uniform and crystallized into the so-called "Received Standard". Williams relates this process to the emergence of a middle class who sought social recognition by defining and standardising "correctness", which had given rise to the spread of a "cult of uniformity" (Williams, 1961/2011, 
p. 262). This process had been promoted by, among other factors, institutions such as the Royal Society's Committee for improving the English tongue and public schools, as well as by practices such as spelling-masters and pronunciation coaches:

Indeed, its naming as standard, with the implication no longer of a common, but of a model language, represents the full coming to consciousness of a new concept of class speech: now no longer merely the functional convenience of a metropolitan class, but the means and emphasis of social distinction. (Williams, 1961/2011, p. 258)

Pierre Bourdieu (1982/1991) has described a similar process of standardization in language use in the context of the democratization of the Nation State in France. In the establishment of the Nation State he identifies the necessary conditions for the formation of a unified "linguistic market", which is dominated by the national language. Great resources were invested in this process in France: Grammar books and dictionaries purified and standardized the national language, while academies and schools propagated it. The national language became mandatory in public spaces and official situations, and consequently acquired a symbolic power: Purified from local accents, it symbolized the unity of the state and the equality of its citizens. The standardization of the language corresponded, from this perspective, to the standardization of the law, sanctioning thereby the equality of all citizens. These citizens, in turn, invested their resources (time, money) in acquiring the national language, in order to obtain access to the life of the State as well as to the national, "unified" job market. The standard language hence represented-at least from an ideological perspectivea gateway for citizens who had been excluded from the centres of power until then. Acquiring the national language at school was indeed a substantial part of the very process of becoming a citizen (Bourdieu, 1982/1991). It is also worth noticing that acquiring the national language still represents for migrants, today, a fundamental prerequisite for acquiring citizenship in many countries. Moreover, the term "acquisition" itself, which is commonly used in expressions such as "foreign language acquisition”, also conceptualizes languages as goods.

The institutionalization of both the national language and the media can be regarded as two related processes which have reinforced each other over time. Andreas Hepp (2009, p. 145) highlights the emergence of territorially defined media cultures by referring to the power of national media in constructing belongings as well as boundaries. He stresses in this regard how the sharing of common media contents within the territory of the Nation State has promoted a feeling of belonging to one and the same community (social dimension) and of being part of a territorial unity (spatial dimension). Moreover, this has reduced the perceived distance to each other among citizens by speeding up communication within the national territory (temporal dimension). If this process has been particularly favoured by the adoption of one common language, the national media has enormously contributed, in turn, to the spread of national "standard" languages. Moreover, the national media have also 
immensely contributed to strengthening the feeling of sharing the standard language, despite the diversity of the many "other" languages (including dialects) that are actually used in everyday life ${ }^{142}$.

When Williams notices, in the 1960s, that the media industries have started to de-centralize the power of national institutions, such as schools and academies, in developing and "normalizing" language use, he recognizes in this process a tension between convergence and divergence which characterizes the story of many other languages and speech communities. He writes in this connection:

\begin{abstract}
We want to speak as ourselves, and so elements of the past of the language, that we received from our parents, are always alive. At the same time, in an extending community, we want to speak with each other, reserving our actual differences but reducing those that we find irrelevant. [...] For the rest, the problems are of emotional tension, and these, while certain to continue, can be much reduced if we learn to look at them openly and rationally, with the rich and continuing history of English as our basis of understanding. (Williams, 1961/2011, p. 268)
\end{abstract}

More than half a century later, these reflections are still very topical, even if, in the intervening period, the technological, political and economic developments mentioned above have produced a different scenario.

In the following section, I will compare a few examples which show the diversification of normative frameworks that affects the notion of "standard English" in current times. These examples illustrate a further pluralization and fragmentation of "linguistic markets" (Bourdieu, 1982/1991) compared with the changes noticed by Williams in 1961, and demonstrate how, while problems of authenticity have remained topical, further transcultural negotiations take place in contexts of superdiversity.

\title{
8.1.1 Pronunciation Workshops and Coaches on Internet Websites
}

The first example relates to Tim's Pronunciation workshop, which was first published by the BBC in 75 episodes and made freely available on the BBC's website (BBC, n.d.). The series displays an overview of the most common phonological features of British English (e.g. assimilation of / $\mathrm{t} /$ followed by /j/, gemination of / $/$, contracted "have", etc.), each one of which is introduced in an episode approximately four minutes long. Every episode starts by introducing Tim, a young "English looking” man with blue eyes and curly blond hair, standing beside "his" garden workshop and welcoming the audience as follows: "Hi. I'm Tim and this is my pronunciation workshop. Here I'm going to show you how English is REALLY ${ }^{143}$ spoken. Come on, let's go inside”. Once

142 An exhaustive and striking account of this process in the Italian context is given by De Mauro, 1963/2017.

143 Capital letters indicate emphasis in the intonation. 
the scene transitions into the workshop, Tim introduces one pronunciation feature by referring to a short anecdote. Then, he announces: "Let's meet some of the people of London."

At this point a video presents about five young people being interviewed in the streets of London who all pronounce the same sentence displaying the mentioned pronunciation trait. Tim then explains the peculiarity of the specific pronunciation feature by describing the corresponding phonological phenomena (e.g. elision, gemination, assimilation, etc.), before turning to a new video which displays five other people "of London" pronouncing a new sentence which exemplifies the same phonological phenomenon. Now it is the turn of the viewer, who is asked to listen and repeat the sentence after each one of the "model speakers". After this, Tim says goodbye and points to the other episodes of the pronunciation workshop. At the end, a funny accident offers Tim the chance to repeat, in a simulated "real talk", more sentences and colloquial expressions entailing the pronunciation trait. Finally, a whiteboard summarizes "Tim's pronunciations notes".

Here it is worth noticing firstly that it is not the entirety of British grammar at the centre of the training, but a specific part of it, namely pronunciation. Furthermore, in addressing "the people of London" as warrantors of authenticity ("how English is REALLY spoken"), the representation of linguistic correctness is rooted in the territorial principle mentioned above. The fictional character of the workshop disregards the fact that London is linguistically one of the most diverse cities in the world and that, for this reason, looking for the standard British pronunciation by interviewing people in the streets of London does not seem such a promising enterprise.

The second example relates to the presentation of pronunciation coaches through internet websites, which I will exemplify by referring to two particular providers which focus on accent reduction in English. The first one, the American Pronunciation Coach, which is offered by a person who presents herself as "Peggy", promises accent reduction in "American” English. Peggy presents herself as a person who has travelled very much, lived in different places, and who thus is greatly familiar, from her own experience, with pronunciation "problems" (American Pronunciation Coach, n.d.) ${ }^{144}$ :

I've lived and worked in Monterey, CA, Tucson, AZ and Albuquerque, NM, in the U.S.- all cultural centers of the American Southwest.

I've also lived in Rome, Italy and traveled and stayed in many places around the world. I love to travel! I'm an artist and a linguist and have kept my hand in the business of teaching ESL/EFL all my life.

144 In this and in the following quotes from this coach, italic characters are in the original text. 
[...] Over the last decade, I have worked only on pronunciation and intonation, and have developed a deep understanding of pronunciation challenges and solutions for people working on their sound in English. I'm very good at targeting your specific issues and giving you guidance in these areas. I'm also skillful with problems related to the American accent: what makes it difficult to produced [sic] and why it's difficult to understand native English speakers.

Recently, I have been working with Maharati [sic], Gujarati, Russian, Chinese, Japanese, Taiwanese speakers on accent reduction and comprehensibility in English, and am familiar with the challenges these speakers face in English. I've also worked with Khazak [sic], Korean, Italian, Portuguese, Swiss, and Arabic clients.

I can teach you to understand why you're having pronunciation problems, how to be more comprehensible in English, and how to maintain your new sound after we are done (American Pronunciation Coach, n.d.).

Peggy addresses quite a differentiated clientele and has specialized on "errors" caused by intersections between "foreign" languages pronunciation and English, with a particular emphasis on "American English". One part of the website is dedicated to the topic "what is causing your accent in English?", which illustrates typical "errors" of a variety of accents including, among others, Arabic, Chinese, French, Indo-Aryan and Korean.

The second example is the Canadian Pronunciation Coach (Canadian Pronunciation Coach, 2020), which addresses speakers of both English as a second or foreign language and Canadian native speakers with specific pronunciation "problems", such as actors:

Canadian actors sometimes lose out on American films because their accents sound too Canadian. A General American accent that's non-region specific can be learned. We work on identifying and incorporating the sounds that distinguish the General Canadian Accent from the General American Accent, as well as identifying distinctly American pronunciations of vocabulary and different cultural references.

Concerning the training which is offered for non-native speakers of English, the website reads:

\section{Accent Elimination vs. Speaking English with Clarity}

Clients who are speakers of English as Another Language sometimes tell me they'd like to lose their accents completely. I always reply, "Your accent is a beautiful part of who you are."

An actor needs to become different people on screen, but you just have to be "you." With pride in your roots, you can alter the parts of your accent that get in the way of your being understood and learn effective speaking skills to communicate with confidence and conviction (Canadian Pronunciation Coach, n.d.).

What can be learnt from such services? In the context of "superdiversity" (Vertovec, 2007) in which patterns of mobility have increased and diversified themselves, individual linguistic repertoires have also become the more and more diverse. Despite 
such diversification, or precisely as a reaction to it, ideologies of correctness and related concepts of standard still regulate processes of in- and exclusion. This is reflected in the power of accent not only in functioning as a gatekeeper with respect to obtaining or failing to obtain career opportunities, but also in promoting or (conversely) hindering interpersonal communication in general, as stressed by one of the Pronunciation Coach websites: "Making adjustments to your accent where it affects intelligibility and adding the elements of English that connect with people in the workplace and the community" (Canadian Pronunciation Coach/ Training, n.d.). However, while Tim's pronunciation workshop refers to the territorial principle in order to derive the "authentic" British pronunciation ("the people of London"), Peggy points at her mobile lifestyle as a guarantor of her "deep understanding” of pronunciation problems. Paradoxically, her story of mobility would enable her to select "good" and "bad" pronunciation traits by signalling speakers' respective patterns of mobility, and in the end by helping them to erase the "bad" ones. Chow (2014, p. 1-17) refers to the efforts made by "xenophonic ${ }^{145}$ nonnative speakers", to adjust their pronunciation in order to become more similar to the native speakers, as a form of "prosthetics" comparable with the treatments which persons of colour undergo in order to whiten their skin. She sees these practices as forms of "racialised languaging" by "conflating the visual and audial significations of the world tones" (Chow, 2014, p. 8). The next section extends these observations on language purity and the question of authenticity by focusing on the negotiations surrounding Hinglish as a postcolonial hybrid language in the context of globalisation and commercialisation of culture.

\subsubsection{Chutnified English, Demotic Dialect or a New Lifestyle Mantra? Transcultural Negotiations of Hinglish}

As argued at the beginning of this chapter, hybridizing language is anything but a rare phenomenon in everyday communication. In linguistics, the variety of terms for addressing this phenomenon-such as, for example, trans-languaging (García \& Wei, 2014), trans-idiomatic practices (Jacquemet, 2005), heteroglossia (Bailey, 2012), codeswitching (Lin \& Li 2012), and, for an overview, Martin-Jones et al. (2012)-testifies to the multiple forms which it can take. But when does a mix of two or more "languages" become acknowledged as a language of its own? In the following section, I will consider this process by referring to the global spread of Hinglish, a hybrid language resulting from the intertwining of English and Hindi. Before looking at multiple ideologies associated with its use, it is important to stress that the ways in which English and Hindi are intertwined in language use differ significantly and that therefore Hinglish is anything but a homogeneous language system. The ideological debates

145 i.e. whose voice sounds as foreign. 
considered in the following show, on the one hand, how processes of standardization and "normalization" are at work as soon as the hybrid speech becomes acknowledged as an autonomous language, and on the other hand, how transcultural negotiations of meaning associated with Hinglish raise questions of authenticity, which, in different contexts both within and outside India, are comparable to and yet different from those addressed in the previous section.

Harish Trivedi (2011) retraces the development of Hinglish from its first written testimonies in the poetry (ghazal) of the India of the late nineteenth century. He relates, in this context, the mix of English and Hindi to a parodic function which carried opposite meanings. On the one hand, in a satire by the poet Ayodhya Prasad Khatri (1857-1905), the insertion of English words into a Hindi text aimed at representing ironically the stereotype of the anglicized upper-class Indians of that time, who looked at acquiring "Englishness" and migrating to London as a means of improving their status and living standards. On the other hand, one finds the parodic representation of "badly spoken" English-speaking Indians by the anglophone Indian poet Nissim Ezekiel (1924-2004), who himself emigrated to London (Trivedi, 2011, pp. XII-XV). Trivedi points at these two opposing ways of appropriating English as the "two poles of Indian attitudes to English and its Indianisation" (Trivedi, 2011, p. $\mathrm{XV}$ ). Turning to more recent times, in the 1960s, Trivedi refers to the use of Hinglish in Shobhaa Dé's gossip column “Nita's Natter” in the English-speaking film magazine Stardust, in which the author, by reviewing Hindi films in English for her Hindispeaking audience, spices up her texts by inserting Hindi words. Trivedi contrasts this use of Hinglish, in which both the author and the reader share a common knowledge of both the languages and their contexts of use, to the use of language by Salman Rushdie, whose practice to “chutnefy English” demonstrates, in Trivedi's view, a lack of knowledge about the original meanings and contexts of use of the Indian words inserted into his English texts. As a result, Trivedi argues, Rushdie ends up exoticizing both his subject matter and the Indian languages, and, by using "the small change of a few Hindi words to authenticate himself in the eyes of his Western readers, for he knows these words and they do not", demonstrating in fact a "very lack of authenticity” (Trivedi, 2011, pp. XVII-XVIII). The examples mentioned by Trivedi are initial testimonies of the written use of Hinglish in a time in which it was not yet recognized as an autonomous "language". They are, nevertheless, very topical with respect to central issues associated with the use of Hinglish today, such as the problem of authenticity and the risk of exoticizing usage of it, or the association between Hinglish and a particular lifestyle.

It was only at the beginning of the 1990s when Hinglish began to be considered as a "proper language". This took place in the context of its increasing use in cinema, television and advertising. Daya Kishan Thussu (2011) relates this process both to the growth of a young, urbanized and culturally hybridized middle class, who is attracted by consumerist life-styles and with increasing purchasing power, and to the liberalization of media and cultural industries in India and the increasing availability of new 
media technologies, such as satellite and cable television. This has attracted transnational media corporations, which, beside the above-mentioned transformations of local audiences, could also take advantage of the generally globalizing tendency of the media market, blurring boundaries between local, diaspora and transnational audiences. The diffusion of Amazon, Netflix and other media-services providers, together with the individualization of media consumption, has increased the forms and the meanings of multilingualism in media products, not only with respect to Hinglish, but also regarding many regional languages used in India. Smith Mehta (2020) points in this regard to the increasing creation, circulation and consumption of "regional" online content in non-Hindi and non-English languages in India. He stresses the potential of such localization strategies with respect to the possibility for the viewers of developing a sense of familiarity with what is represented on the screen, especially in the context of the Indian government's nationalistic efforts to promote Hindi (Mehta, 2020, p. 116). Thussu (2011) expresses instead a more critical position in this regard and speaks of the "Murdochisation" of the media, by referring to the expansion of global corporations which, despite formally adopting localization strategies which claim to be addressing national or local interests, in fact propagate a dominant neoliberal ideology that undermines "the public-service ethos and the empowering potential of TV in a country that is still home to the largest segment of the world's poorest people" (Thussu, 2011, p. 111). Hinglish is, however, not only associated with the emergence of neoliberalism and consumerist attitudes. Rita Kothari and Rupert Snell (2011), who offer a multifaced perspective on the development of Hinglish by comparing interdisciplinary scholarly and practitioners' insights, examine a very heterogeneous panorama and note "almost irreconcilable ideologies". Beside the aforementioned strand of thought which considers Hinglish as a form of Westernization and a superficial exoticization of Indian culture that undermines its authenticity, other observers have acknowledged, particularly in more recent times, the symbolic power of Hinglish in negotiating new spaces of identity that intertwine the local and the global. Kothari (2011), for example, has stressed a change in the way in which Hindi and English have been used in Hindi cinema from the post-Independence period to contemporary times:

I argue that during this period [i.e. of post-Independence] Hindi cinema used English with connotations of cultural alienation such as Westernisation and class elitism, giving way in the last two decades to less anxious uses of Hinglish - creolised, constructed, and promoted as a language of fun-on-Indian-terms. While the association with class persists, it moves from signifiers of exclusivity to aspiration, as more people are now able to access that class. If the class theme represents continuity, the discontinuity lies in the shift of perception of English from being a language "outside" the sphere of everyday Indianness (1950s-1980s) to Hinglish as simultaneously Indian-and-global, embracing des and pardes, nation and diaspora in cinema after the 1990s. (Kothari, 2011, p. 113) 
This view is shared by Prateek and Amit Sarwal (2014), who stress that the growth of Hinglish cinema in the 1990s represents a reaction to the nationalist orientation of Hindi mainstream cinema which, by standardizing Hindi and purifying it from the "contamination" of other languages, had contributed to the affirmation of a "Hindi public sphere" (Orsini, 2002) involving "discursive and institutional spaces, a common language, a set of procedural principles (e.g. respect for reasoned argument and open debate), some activism, and the awareness of a public out there" (Orsini, 2002, pp. 11-12). Moreover, Prateek and Amit Sarwal (2014) highlight how, in opposition to mainstream masala cinema, which had idealized the village and proposed an escapist attitude with respect to both the colonial experience and the problems of everyday life, Hinglish cinema recalls the realistic taste of the (New Wave) art cinema of the 1960s and 1970s, by critically looking at the village and deconstructing its idealized image, after Bollywood has romantically represented it as an incorruptible site:

\footnotetext{
Hinglish cinema revamps city and presents it as a global village where people from different linguistic backgrounds intermingle. It provides educated Indians access to a world that the Hindi- dominated world of Bollywood denied them earlier. [...] This global character of the city is emphasised through chutnified English, which is spoken by Indians in these cities. In these movies, one encounters a continuum of English: from Bazaar-English, Butler-English, BabooEnglish, diasporic English to near native English. These displaced people - linguistically and otherwise - are in their camps or settlements in the urban areas and such settlements are on the increase. (Sarwal \& Sarwal, 2014, pp. 167-168)
}

The crucial transition from the simple insertion of English words into Hindi screenplays to the affirmation of a hybrid language, in which English and Hindi flow into each other, has been dated back to the 1990s (Kothari, 2011). Beside matters of authenticity, which have already been mentioned, questions of language competence have also been raised in this regard. Will the spread of Hinglish challenge speakers' competence in English, Hindi and other languages? Snell (2011, p. 36), for example, expresses his worry about a "dilution of the genius of Hindi, and irreversible damage to its ecological balance”, by highlighting how loans from English are not a simple addition to Hindi, but are actually displacing Hindi words. This worry is shared by Trivedi (2011), who rejects the status of "language” for Hinglish: "The major peril of thus promoting a demotic dialect [my italic] like Hinglish is that we may soon be left with neither Hindi nor English but just Hinglish” (Trivedi, 2011, p. XXIII). A similar position has been expressed by the late Vinod Mehta, journalist and former founding editor-in-chief of the Indian English-speaking general interest magazine Outlook, who stated in an interview to the Guardian International: "It's a terrible slide in quality when respectable publications use this hotchpotch of English and Hindi. We produce journalism in English” (Ramesh, 2008).

A further dispute regards the future of Hinglish as a marginalized or, contrarily, a global language. Trivedi (2011) compares, for example, the destiny of Hinglish with that of Urdu in the Indian subcontinent. Originating as a hybrid language which mixed 
Persian and Indian local languages, in a period in which Persian was the ruling language spoken by a tiny elite, Urdu, which held for a while a high status because of its closeness to the "cosmopolitan Persian", eventually lost its power, "mainly because it retained the courtly sophistication of Persian and this remained largely incomprehensible to the masses who spoke Hindi” (Trivedi, 2011, p. XXIV). An opposite prediction has been expressed by the Indian journalist Binoo K. John, who has documented the rise of Hinglish, in an interview to the Guardian International: "Within two decades Hinglish would become a globally accepted form. More and more people will use it without fear of being laughed at. We are not afraid of speaking in the way that we want anymore" (Ramesh, 2008). This proud act of empowering Hinglish and distancing it from British English (and the attitude of considering British English as "the" standard), recalls the process of transformation of American English in the eighteenth and nineteenth centuries. As highlighted by Kahane (1982), in the decolonized society of the New World, spoken American English transformed from a substandard (with respect to elite British English) to a prestige language by its symbolizing the language of an "Everyman" in a society that aimed at being for the "Everyman". By stating that "the present is the age of simplicity of writing in America", Benjamin Rush, signer of the United States Declaration of Independence, emphasized precisely "the decline in Anglophilia, the standardization of informal speech, the levelling of social dialects, the integration of foreign elements" (Kahane, 1982, p. 230).

Is Hinglish going through a comparable standardization process while becoming a "global code"? The perspective of young academics both within and outside India seems to confirm this trend. Pal and Mishra (2011), who reflect on their experience as students at the Mudra Institute of Communications in Ahmedabad, an elite Indian institution of higher learning, considers Hinglish "not just as a language but also a new lifestyle mantra [my italic]” (Pal \& Mishra, 2011, p. 160). Indeed, Hinglish is spreading in the universities, and not only in India, both as a language of instruction and in language teaching. The Portsmouth College in England, for example, has introduced classes of Hinglish in 2017. What was at the beginning an experimental initiative has turned to be part of the regular offer from the 2018-2019 academic year, because of its popularity among the students (Times of India, 2018). A BBC service (BBC News, n.d.) reporting on this, displays a heterogeneous group (in terms of gender, religion and ethnicity) of students practising Hinglish in a typical class of language teaching. The choral repetition of specific linguistic traits and the comments of the interviewed students indeed recall the idea of a "new lifestyle mantra" which was proposed by Pal and Mishra. One student, for example, by displaying the pronunciation that was taught by Tim in his pronunciation workshop, states: “I'm in this bubble of Portsmouth and I want to get out of this bubble". In another case, while the teacher explains the way in which Hindi and English intertwines in an advertising text, a subtitle points out: "India is the world's seventh largest economy so young people are keen to look for international opportunities". Two interventions by members of the academic staff highlight that it is not the language competence itself to be considered 
particularly important ("When it is Hinglish is about Hindi and English, but it could be any language"), but rather the acquisition by the students of a particular "cosmopolitan attitude":

It's great to hear that our future generation of workers are actually taking into consideration what's happening around us. So they are socially aware but they are looking at ways in which they can equip themselves to be better prepared for situations that they may be faced with. (BBC News, n.d.)

These last words by the interviewee are accompanied by the image of a crowded Indian market. Against this background, a concluding subtitle reads: "Hinglish is India's business language of choice”.

While some observers neglect the status of a "language" for Hinglish, its practices of standardization and its use not only in cinema, television and advertising but also in contexts of education both within and outside India, would suggest that Hinglish occupies anything but a marginal position in globalized "linguistic markets". Should this be considered a progress in normalizing linguistic diversity in public spheres, or does the standardization of Hinglish and its transformation into an acknowledged "language" only reproduce a pattern of homogenization of diversity? In the next section, two more examples illustrating the negotiation of national, minority and local languages in both multi- and translingual mediascapes ${ }^{146}$ will offer more insights for discussing this question in the final section.

\section{2 “Parallel Monolingualism" vs. Performed Diversity}

The need to communicate in an extending community, and the value acquired by English in a globalized "linguistic market" (Bourdieu, 1982/1991), have been variously contrasted by claiming that the attachment to specific linguistic resources (national or minority languages, dialects, etc.) should be understood as territorially bound to a particular identity. In defence of local, regional or national features of identity, diversity has often been held up as an example of a resisting ideology with respect to the alleged homogenization brought about by globalization. In this section, I will compare different ways of handling linguistic diversity in public spheres with the aim

146 The distinction between multi- and translingual mediascapes, which will be further illustrated in section 3, aims at contrasting two different ways of handling linguistic diversity in mediated communicative spaces. Whereas the term "multilingual" stresses the juxtaposition of single "languages" (e.g. Spanish, English, etc.) which do not intertwine, the term "translingual" refers to hybrid language use (Pelillo-Hestermeyer 2018a). The term mediascape (Appadurai, 1996) refers instead to transnational media flows whicoss national boundaries and which articulate themselves in an asymmetrical, polycentric geometry of networks. 
of discussing how diversity and otherness are regulated, performed and negotiated in the corresponding contexts, and to what extent specific practices, which professedly aim at enhancing diversity, in fact end up stimulating power asymmetries and conflicts.

In institutional contexts, a range of policies and politics has been developed for protecting specific national or minority languages from being marginalized or even replaced by "global" English in many contexts of use. Art. 3(3) sub-para. 4 of the Treaty on European Union, for example, reads: "It [the EU] shall respect its rich cultural and linguistic diversity, and shall ensure that Europe's cultural heritage is safeguarded and enhanced" (Official Journal 2012 C 326/13). Linguistic Diversity is conceived in this context as resulting from the sum of European "heritage" languages, which are defined on a territorial basis, that is, consisting of the languages historically present on the European territory. Among these languages, national majority languages (and their corresponding speakers) benefit from greater protection than do minority languages, for example by being considered as official languages of the European Union, which guarantee, among other aspects, the right to use these languages in the communication with the European institutions, according to Art. 41(4) of the Charter of Fundamental Rights of the European Union: "Every person may write to the institutions of the Union in one of the languages of the Treaties and must have an answer in the same language" (Official Journal 2012 C 326/391). This territorial principle is often addressed while reasoning about language policies. A recent example is offered by the discussions surrounding the status of English after Brexit and whether it should remain a working language of the European Union, given that Ireland would remain the only member State in which English functions as the nation's main language. Moreover, the "heritage principle" does not acknowledge speech communities which have been present in the European Union from more recent times. A further example of resistance to English in an international institutional context is offered by Art. 11 of the UN General Assembly Resolution 67/292 on Multilingualism, which

emphasizes the importance of making use of all the official languages of the United Nations, ensuring their full and equitable treatment in all the activities of the Department of Public Information of the Secretariat, with the aim of eliminating the disparity between the use of English and the use of the five other official languages, and in this regard reaffirms its request that its Secretary General ensure that the Department has the necessary staffing capacity in all the official languages to undertake all of its activities. (General Assembly Resolution 67/292)

The above-mentioned policies shall guarantee full and equitable treatment to specific "official languages", yet not to the "languages" of all members of the corresponding institutions. In the European Union, a differentiation between the currently 24 "official languages" and the three "working languages" (English, French and German) has brought about asymmetries between speakers of working, official and minority languages. A conflict regarding the mandatory use of one of the three working languages in recruitment processes at the European institutions has driven, for example, 
Italy and Spain to the point of suing the European Commission and succeeding in a case at the Court of Justice of the European Union in 2019 ${ }^{147}$. As it emerges from these examples, the promotion of linguistic diversity in terms of safeguarding specific heritages is also strongly related to the investment of resources. Bourdieu's concept of the "linguistic market" has not lost, in this regard, its applicability, since diversity policies and politics are also a means of preserving a more central, or negotiating a less marginal, position in this regard.

When we now turn to mediatized public spheres, the European news channel Euronews in 2017 started a process of transformation from a "glocal" journalism - that is, one in which contents were adapted (including linguistically) to local audiencesto a new model, based on twelve different "cross-platform" editions, each one of which is characterized by the use of a specific language, as explained on the website:

\begin{abstract}
Since its launch in 1993 in Lyon, France, Euronews has developed the world's first "glocal" news brand, i.e. the first global media that adapts itself to the expectation of its multiple local audiences. In 2017, Euronews replaced its model that had been at the core of its offer since its inception by the launch of 12 distinct cross-platform editions. The different editions enable Euronews to deliver tailored content that is relevant to each audience. With a team of 600 journalists of more than 30 different nationalities, Euronews' 12 editions cover world news 24/7 in Arabic, English, French, German, Greek, Hungarian, Italian, Persian, Portuguese, Russian, Spanish and Turkish. (Euronews, n.d.)
\end{abstract}

Language diversity is considered in this regard as the fundamental means of sorting audiences, and as an important criterium for selecting contents which are considered to be of interest for a corresponding community. By only partly overcoming the assumption that one culturally (and linguistically) homogeneous community corresponds to one geographic territory, sorting audiences by identifying "language communities" reproduces an idea of diversity based on the juxtaposition of single and monolithic cultural systems, thus perpetrating the nexus of "one language-one public sphere", as was illustrated in section 2 with respect to the institutionalization of, respectively, the national language and the media ${ }^{148}$. A similar attitude to linguistic diversity can be observed by looking at multilingual practices in the context of the French-German television network ARTE, which commonly offers shared content in French and German by dubbing. However, since 2015 ARTE has progressively extended to include four other languages (Italian, English, Polish and Spanish), also thanks to funding by the European Union, which aims at fostering "EU integration through culture by providing new subtitled versions of selected TV programmes across Europe” (ARTE, n.d.). The use of subtitles instead of dubbing, which allows the audience to access

147 Case C-621/16 P, Commission v. Italian Republic, ECLI:EU:C:2019:251.

148 For a more extensive analysis of such practices, see Pelillo-Hestermeyer 2018a and 2015. Moreover, Pelillo-Hestermeyer/Cismondi in this volume considers a similar attitude to diversity with respect to diversity in science. 
contents in the original language(s), contributes not only to raise awareness towards linguistic differences, but also to enrich audiences' linguistic repertoires by increasing their understanding of languages that might otherwise be considered as "foreign". All in all, as I have argued in previous works (Pelillo-Hestermeyer 2018a, 2018b and 2015), increasing the visibility of, instead of hiding, linguistic diversity contributes to the strengthening of more tolerant and open attitudes towards "the Other". In this context, it appears as a paradox that the multilingual offer is presented on the ARTE's website by recurring to the following paratext: "ARTE in 6 languages - To $70 \%$ of Europeans in their own language [my italics] (ARTE, n.d.).”

Instead of emphasizing that the subtitles-strategy allows European audiences to access shared media content in the original languages, thus enhancing the visibility of European diversity, the paratext not only does not mention this possibility, but implicitly assumes that the audiences would display a completely opposite attitude, namely that of being interested in receiving the contents only "in their own language". Furthermore, it assumes that Europeans each "have" one language, thus recalling the ideology of "one language-one community" that we saw to be illustrated with respect to European language policy. This way of handling linguistic diversity in mediated public spheres has been addressed as "parallel monolingualism" (Heller, 2006), or "pluralised monolingualism" (Makoni \& Pennycook, 2007), since it relies on a conceptualization of diversity as the juxtaposition of separate monolingual speech communities.

In Pelillo-Hestermeyer (2018a) I contrasted this phenomenon of "parallel monolingualism" with other ways of handling linguistic diversity in particular transcultural journalism in the Mediterranean, where I described it in particular as "translingua", or "multilingua franca", using the term coined by Makoni and Pennycook (2007). Both these terms aim at emphasizing the fact that plurality and hybridity are essential characters of language use and that, for this reason, linguistic diversity would not need any pluralization of the term "language" (e.g. multilingualism). One of the media products which exemplify this different approach to linguistic diversity in journalism is a weekly radio magazine in Corsican and Italian, which is co-produced by the Italian and French broadcasters RAI and France Bleu. Mediterradio-the title of the show-is presented as a weekly magazine of the Mediterranean islands Corsica, Sardinia and Sicily, although journalists from Tunis and Malta also participate in the show periodically. Instead of addressing the audiences by separating them according to "language communities", the three anchors, who are located in the respective islands, use Italian and Corsican without translating or dubbing, by relying on the inter-comprehension between the two languages, and thus emphasize the mutual proximity in their linguistic diversity. When the colleagues participate in the show from Tunis and Malta, they use Italian as a lingua franca. Mutual understanding between speakers of Italian and Corsican is possible, but not expected without a certain effort in speaking particularly clearly and listening particularly carefully. Moreover, it requires an open attitude towards the different phonologies, 
as well as the acceptance of missing meanings from time to time. Certainly, listening regularly to the magazine improves one's individual translingual understanding. However, the main aim of the magazine does not consist of enhancing audiences' linguistic skills, but rather presenting a different, and specifically an "insular” Mediterranean, perspective on current events. Rather than focussing on juxtaposition and on a territorial mapping of speech communities, this way of handling diversity relies on polycentricism and connectivity, which can be observed in interactional, discursive and journalistic practices ${ }^{149}$. The appropriation of a more central position in reporting about and from the Mediterranean emphasizes both diversity and familiarity without levelling, standardizing or normalizing differences, while also setting itself in opposition to the mainstream media reports in national and transnational public spheres (Pelillo-Hestermeyer, 2018a).

Such an idea and practice of diversity should not be seen as necessarily linked to mixing two or more "languages". As the examples in this chapter show, promoting or hindering linguistic diversity is more about "doing diversity" vs. "doing otherness" by representing and performing language(s).

\subsection{Concluding Remarks}

At the beginning of this chapter, linguistic diversity was acknowledged to be one of the most common experiences in human life. This premise was aimed at emphasizing how, nevertheless, various ideologies at the core of mediatized language use lead either to representing diversity as something exceptional, or to standardizing and homogenizing hybrid language use. This is related, historically, to the institutionalization process of, respectively, national language(s) and media system(s), which has accompanied the formation of the nation state. After this discussion, I referred to the comments by Raymond Williams in 1961, who noticed that a new player, "the media", was starting to influence, de-centralize and pluralize the concept of "standard" codified and disseminated by institutions, such as schools and academies. Today, media can no longer be addressed as autonomous agents which directly influence the value of "languages", as they did when Williams' The Long Revolution was first published in the early 1960s. It appears rather to be more appropriate to look at practices of representing, disputing and standardizing diversity in the context of the overall transformation of public spheres, by referring to the four meta-processes indicated by Krotz (2009), namely globalization, mediatization, commercialization and individualization ${ }^{150}$. Bourdieu's concept of the "linguistic market" helps us to

149 For a more detailed analysis of interactional, discursive and journalistic practices, see PelilloHestermeyer 2018a.

150 "Each of these meta-processes is an ordering principle, which helps us to think of specific events 
understand the negotiations of power that are operative in this regard: Resistance towards the commercialization of culture, personified by the rise of global English (but also of Hinglish, even if in a minor tone), is expressed by various policies and politics that are aimed at safeguarding "heritage" languages, as exemplified by the examples in section 8.2. Practices of "parallel monolingualism” (Heller, 2006), or "pluralized monolingualism" (Makoni \& Pennycook, 2007), follow a similar pattern by following the territorial principle in conceiving and promoting diversity by juxtaposing different "speech communities". The different examples illustrated demonstrate that, despite the different forms taken by standardization in different contexts, the homogenizing ideology at the core remains a constant. Questions of authenticity, which have emerged in all the discussed cases, demonstrate this. In Tim's Pronunciation Workshop, it is the territorial principle to be addressed as a guarantor of the "right" pronunciation ("let's meet the people of London"), a homologizing idealization which distorts the "superdiversity" which actually characterizes the English metropolis. In this case, the commercial pronunciation coaches point at accent reduction, which is in fact a way of standardizing diversity by deliberately selecting, case by case, which pronunciation traits can be preserved and which need to be erased. At the same time, the coaches emphasize how important it is "to be yourself" by altering one's native pronunciation. The principle of authenticity becomes individualized in this context: In a globalized "linguistic market" it is the "right" mix between specific linguistic resources to be of particular value. A personal coach should help, in this context, to skilfully select and erase only the "bad" phonological traits. This recalls what Blommaert (2010, p. 47) writes regarding linguistic inequality in the context of globalization:

The crux of the matter is that we need to think of issues such as linguistic inequality as being organized around concrete resources, not around languages in general but specific registers, varieties, genres. And such concrete resources follow the predicament of their users: when the latter are socially mobile, their resources will follow this trajectory; when they are socially marginal, their resources will also be disqualified. In both cases, the challenge is to think of language as a mobile complex of concrete resources.

As a matter of fact, one of the pronunciation coaches pinpoints her mobile lifestyle and her passion for travelling as one of the major sources of her knowledge and ability. The dispute surrounding the rise of Hinglish confirms a similar polarization between, on the one hand, speakers who advocate the territorial principle as a guarantor of authenticity, and on the other hand, those who see it as a "new lifestyle mantra”, regardless of how "correctly" one can use it. Those who advocate the territorial principle perceive as authentic only the use of Hinglish by speakers who know the

and developments as belonging together, as each one takes place in specific fields of culture and society and then affects many other fields" (Krotz, 2009, pp. 24-25). 
original (that is, territorialized) meanings and contexts of use of both the languages in question, namely Hindi and English. They perceive as exoticizing the use of Hinglish by people who might not have the same "competence" in both languages, and in particular display a lesser "competence" of Hindi than their competence in English. On the other side, those who see Hinglish as a means of "being local and global" display multiple appropriations and re-signifying practices of Hinglish, as it typically occurs with global resources. Hinglish is perceived by some Indian observers as a symbol that unifies nation and diaspora, the (post)colonial experience and the global future of India. In England, however, young learners of Hinglish are not aware of this "trajectory" (Blommaert, 2010, p. 47, quoted above), and only perceive it as a way of "going global" by looking outside of England. This happens while learners of English try to get rid of their linguistic "otherness" by attending pronunciation coaches who assist with British English, the global language. In both cases, issues of authenticity and class permeate standardization practices. However, while defining a specific prestige language according to the territorial principle, continues a tradition originated within the consolidation of the nation state, relating prestige and class to a specific lifestyle is a more recent phenomenon, inserted into the overall "meta-process" (Krotz 2009) of commercialization of culture. In this context, while Hinglish displays the "right mix" to be considered "local and global", other "languages" do not. Worries concerning the "loss of competence" in both English and Hindi, originate, among others, from looking at other hybrid "languages" which, both within and outside India, have become marginalized.

At the same time technologies such as the Internet and digitalization more broadly have also opened up new opportunities for linguistic diversity in less institutionalized and mediatized public spheres. The radio magazine Mediterradio represents a symptomatic example of a new mode of "doing diversity" by opposing vernacular sensitivities to, respectively, the monolingualism of national mainstream media and the "parallel monolingualism" of transnational mainstream media. In this case, centres and peripheries become re-negotiated in a transnational and "fluid" public sphere. Certainly, this sort of "translingua” (Pelillo-Hestermeyer 2018a) represents a niche phenomenon. Research on mediated multilingualism (Kelly-Holmes \& Milani, 2011b) highlights in this regard that most of the deconstructionist critique, as is expressed by post-structuralist sociolinguistics, of the hegemonic practices of mediatized multilingualism (e.g. the hegemonic idea of speech community as a homogeneous group, the tabooification of hybrid speech, or the need to categorize languages), has not yet reached the media-makers. They notice in this regard that media-makers are not essentially pitted against linguistic diversity but are rather used to adopting conceptual frameworks that, we have seen, are so ideologically marked. Kelly-Holmes and Milani go so far as to look at this gap as "one of the key challenges for scholarship on multilingualism and/in the media in the near future" (Kelly-Holmes \& Milani, 2011b, p. 475). 
Against this background, this chapter aims at raising awareness, also outside of academia, about ideological frames at work by "doing diversity" or "doing otherness" in mediatized public spheres and in everyday life in general. Mixing "languages" might appear, in this context, to be the ordinary and future default aspect of this subject area.

\section{References}

Androutsopoulos, J. (Ed.). (2014). Mediatization and sociolinguistic change. De Gruyter.

American Pronunciation Coach. (n.d.). Retrieved March 2, 2020 from https://americanpronunciationcoach.com/welcome/aboutyourcoach

Appadurai, A. (1996). Modernity at Large: Cultural Dimensions of Globalization. Univ. of Minnesota Press.

ARTE. (n.d.). What we do. Retrieved March 24, 2020, from https://www.arte.tv/sites/en/corporate/ what-we-do

Bailey, B. (2012). Heteroglossia. In M. Martin-Jones, A. Blackledge, \& A. Creese (Eds.), The Routledge Handbook of Multilingualism (pp. 499-520). Routledge.

BBC (n.d.). Tim's Pronunciation Workshop. Retrieved March 2, 2020, from http://www.bbc.co.uk/ learningenglish/english/features/pronunciation/tims-pronunciation-workshop-ep-30

BBC News (n.d.). Hinglish taught in UK 'for first time'. You Tube. Retrieved March 24, 2020, from https://www.youtube.com/watch?v=GTqvzmlfFqw\&feature=youtu.be

Blommaert, J. (2010). The Sociolinguistics of Globalization. Cambridge University Press.

Blommaert, J. (2013). Ethnography, superdiversity and linguistic landscapes: chronicles of complexity. Multilingual Matters.

Blommaert, J., Collins, J., \& Slembrouck, S. (2005). Spaces of multilingualism. Language and Communication, 25, 197-216.

Blommaert, J., Kelly-Holmes, H., Lane, P., Leppänen, S., Moriarty, M., Pietikäinen, S., \& PiirainenMarsh, A. (2009). Media, Multilingualism and Language Policing: an Introduction. Language Policy, 8(3), 203-207.

Blommaert, J., Rampton, B., \& Spotti, M. (Eds.). (2011). Language and Superdiversities (Vol. 13 (2)): UNESCO.

Bourdieu, P. (with Thompson, J. B.) (1991). Language and symbolic power. Polity (Original work published 1982. Ce que parler veux dire.)

Busch, B. (2012). Das sprachliche Repertoire oder Niemand ist einsprachig. Drava.

Butler, J. (2006). Haß spricht: zur Politik des Performativen. Suhrkamp.

Canadian Pronunciation Coach (n.d.) Retrieved March 2, 2020, from http://www.canadianpronunciationcoach.com

Canadian Pronunciation Coach/ Training (n.d.). Retrieved March 2, 2020, from http://www.canadianpronunciationcoach.com/training/method

Chow, R. (2014). Not like a Native Speaker. On Languaging as a Postcolonial Experience”. Columbia University Press.

De Mauro, T. (2017). Storia linguistica dell'Italia unita. GLF editori Laterza. (Original work published 1963).

Derrida, J. (1996). Le monolinguisme de l'autre. Éditions Gallilée.

Euronews (n.d.). About Euronews. Retrieved March 24, 2020, from https://www.euronews.com/ about

Foucault, M. (1972). The archaeology of knowledge and the discourse on language. Pantheon Books. 
García, O., \& Wei, L. (2014). Translanguaging: language, bilingualism and education. Palgrave Macmillan.

General Assembly Resolution 67/292, Multilingualism, A/RES/67/292. Retrieved April 3, 2020 from https://treaties.un.org/doc/source/a_res_67_292-Eng.pdf

Heller, M. (2006). Linguistic Minorities and Modernity: a Sociolinguistic Ethnography. Continuum.

Hepp, A. (2009). Differentiation: Mediatization and Cultural Change. In K. Lundby (Ed.), Mediatization: Concepts, Changes, Consequences (pp. 139-157). New York: Peter Lang.

Hepp, A. (2014). Mediatization. A Panorama of Media and Communication Research. In J. Androutsopoulos (Ed.), Mediatization and Sociolinguistic Change (pp. 49-66). De Gruyter.

Jacquemet, M. (2005). Transidiomatic practices: Language and power in the age of globalization. Language and Communication, 25, 257-277.

Kahane, H. (1982). American English: From a Colonial Substandard to a Prestige Language. In B. B. Kachru (Ed.), The other tongue: English across cultures (pp. 229-236). University of Illinois Press.

Kelly-Holmes, H., \& Milani, T. M. (Eds.). (2011a). Thematising Multilingualism in the Media. Journal of Language and Politics. Special issue, 10(4), Benjamins.

Kelly-Holmes, H., \& Milani, T. M. (2011b). Thematising Multilingualism in the Media. In H. Kelly-Holmes \& T. M. Milani (Eds.), Introduction: Thematising Multilingualism in the Media. Journal of Language and Politics. Special issue, 10(4), 467-489. Benjamins.

Kothari, R. (2011). English AAJKAL: Hinglish in Hindi cinema. In R. Kothari \& R. Snell (Eds.), Chutnefying English: The phenomenon of Hinglish (pp. 112-127). Penguin Books India.

Kothari, R., \& Snell, R. (Eds.). (2011). Chutnefying English: the phenomenon of Hinglish. Penguin Books India.

Krotz, F. (2009). Mediatization: A Concept with which to grasp Media and societal Change. In K. Lundby (Ed.), Mediatization: Concept, Changes, Consequences (pp. 21-40). Peter Lang.

Lin, A. Y. M., \& Li, D. C. S. (2012). Codeswitching. In M. Martin-Jones, A. Blackledge, \& A. Creese (Eds.), The Routledge Handbook of Multilingualism (pp. 470-481). Routledge.

Livingstone, S. (2009). On the mediation of everything. Journal of Communication, 59(1), 1-18.

Lundby, K. (Ed.) (2009). Mediatization: Concept, Changes, Consequences. New York: Peter Lang.

Makoni, S., \& Pennycook, A. (2007). Disinventing and Reconstituting Languages. In S. Makoni \& A. Pennycook (Eds.), Disinventing and Reconstituting Languages (pp. 1-41). Multilingual Matters.

Martin-Jones, M., Blackledge, A., \& Creese, A. (Eds.). (2012). The Routledge Handbook of Multilingualism. Routledge.

Mehta, S. (2020). Localization, diversification and heterogeneity: Understanding the linguistic and cultural logics of Indian new media. International Journal of Cultural Studies, 23(1), 102-120.

Official Journal 2012 C. Retrieved April 3, 2020, from https://eur-lex.europa.eu/LexUriServ/ LexUriServ.do?uri=0J:C:2012:326:FULL:EN:PDF

Orsini, F. (2002). The Hindi public sphere 1920-1940: language and literature in the age of nationalism. Oxford Univ. Press.

Pal, S., \& Mishra, S. (2011). Hinglish and Youth: A campus perspective. In R. Kohari \& R. Snell (Eds.), Chutnefying English: The phenomenon of Hinglish (pp. 161-175). Penguin Books India.

Pelillo-Hestermeyer, G. (2015). Mehrsprachiger und lokaler Radiojournalismus: ein interdisziplinärer Ansatz zur Förderung von Medien- und Sprachkompetenzen. In S. Witzigmann \& J. Rymarczyk (Eds.), Mehrsprachigkeit als Chance: Herausforderungen und Potentiale individueller und gesellschaftlicher Mehrsprachigkeit (pp. 273-285). Peter Lang.

Pelillo-Hestermeyer, G. (2018a). Language diversity in a Mediterranean mediascape. Discourse, Context \& Media, 24, 109-116. https://doi.org/10.1016/j.dcm.2018.02.006

Pelillo-Hestermeyer, G. (2018b). Transkulturelle Philologie: Über das Potential eines Überdenkens fachlicher und nationaler Grenzen. In J. Ettrich \& M. L. Mäder (Eds.), Dialogpotentiale kulturwissenschaftlicher Forschung in den Fremdsprachenphilologien (pp. 157-172). Lang. 
Ramesh, R. (2008, October 24). English is recast in Indian films. The Guardian. Retrieved April 4, 2020, from https://www.theguardian.com/education/2008/oct/17/bollywood-english

Sarwal, P., \& Sarwal, A. (2014). Hinglish cinema: The confluence of East and West. In V. Kishore, A. Sarwal, \& P. Patra (Eds.), Bollywood and its Other(s) (pp. 161-173). Palgrave MacMillan.

Snell, R. (2011). Hindi: Its threatened ecology and natural genius. In R. Kothari \& R. Snell (Eds.), Chutnefying English: The phenomenon of Hinglish (pp. 22-36). Penguin Books India.

Thussu, D. K. (2011). Towards a political economy of Hinglish TV. In R. Kothari \& R. Snell (Eds.), Chutnefying English: The phenomenon of Hinglish (pp. 98-111). Penguin Books India.

Times of India. (2018, March 10). UK college to expand Hinglish course offering. Retrieved April 4, 2020, from https://timesofindia.indiatimes.com/uk/uk-college-to-expand-hinglish-courseoffering/articleshow/63244821.cms

Trivedi, H. (2011). Forward. In R. Kothari \& R. Snell (Eds.), Chutnefying English. The Phenomenon of Hinglish (pp. VII-XXVI). Penguin Books India.

Vertovec, S. (2007). Super-diversity and its implications. Ethnic and Racial Studies, 29(6), 1024-1054.

Vertovec, S. (Ed.). (2010). Anthropology of migration and multiculturalism: new directions. Routledge.

Williams, R. (2011). The Long Revolution. Parthian. (Original Work published 1961). 